Wilfrid Laurier University

Scholars Commons @ Laurier

\title{
The dynamic nature of coping with gender discrimination: Appraisals, strategies and well-being over time
}

Mindi D. Foster

Wilfrid Laurier University, mfoster@wlu.ca

Follow this and additional works at: https://scholars.wlu.ca/psyc_faculty

Part of the Psychiatry and Psychology Commons, and the Social Psychology Commons

\section{Recommended Citation}

Foster, Mindi D., "The dynamic nature of coping with gender discrimination: Appraisals, strategies and well-being over time" (2009). Psychology Faculty Publications. 48.

https://scholars.wlu.ca/psyc_faculty/48

This Article is brought to you for free and open access by the Psychology at Scholars Commons @ Laurier. It has been accepted for inclusion in Psychology Faculty Publications by an authorized administrator of Scholars Commons@Laurier. For more information, please contact scholarscommons@wlu.ca. 
Running head: Coping with gender discrimination over time

The dynamic nature of coping with gender discrimination:

Appraisals, strategies and well-being over time 


\begin{abstract}
Female introductory psychology students at a Canadian university $(\mathrm{N}=31)$ participated in a lab simulation of discrimination, completed coping and well-being measures and then an online survey of well-being one year later. Expectations were that active (inactive) coping would initially be related to decreased (increased) well-being. A reverse pattern was expected for relationships between coping and well-being one year later. Results showed that among those perceiving high pervasive discrimination, active and inactive coping was related to decreased well-being immediately after the discrimination was portrayed, but among those perceiving low pervasiveness inactive coping was related to increased well-being. One year later inactive coping was related to decreased well-being among those perceiving high pervasiveness. Implications for short and long-term coping were discussed.
\end{abstract}

Keywords: gender discrimination; coping; longitudinal; well-being 
The dynamic nature of coping with gender discrimination:

Appraisals, strategies and well-being over time.

\section{Introduction}

Whereas most empirical research on discrimination examines its psychological effects at one point in time (e.g., Foster, 2000), the present study used Lazarus and Folkman's (1984) dynamic approach to coping to understand how the process of coping with gender discrimination may change over time. This theory argues that because the process of coping with a stressor changes over time, certain appraisals and strategies may be effective at one point in the process but not at another. This study therefore portrayed a lab situation of gender discrimination to Canadian undergraduate women, assessed their subsequent appraisals, coping strategies and well-being, and one year later asked them to complete an online survey of their well-being. It was expected that the strategies that may enhance (or reduce) well-being at the time of the discrimination may not have the same benefits (or detriments) on well-being one year later.

\section{Background}

One of the unique characteristics of gender discrimination is that it occurs in many contexts in women's lives. Not only can women experience discrimination at work or from strangers, but women often live with and love (e.g., brothers, fathers, sons, romantic partners) members of the group that has historically oppressed them. For examples, women in both Canada (Foster, in press) and the U.S. (Swim, Hyers, Cohen \& Ferguson, 2001), report feeling excluded by trusted individuals in their social networks. In addition, unlike many isolated stressors such as a bad grade or a move, both Canadian (Foster, 2001, in press) and American 
women (Branscombe, Schmitt \& Harvey, 1999; Landrine, Klonoff, Gibbs, Manning, \& Lund, 1995) expect to encounter discrimination repeatedly in the future. It may not be surprising therefore, that discrimination can have a negative impact on well-being; in both Canada (Foster, 2000; Matheson, Jorden \& Anisman, 2008) and the U.S. (Klonoff, Landrine \& Campbell, 2000; Krieger, 1990; Landrine, et al., 1995) discrimination has been associated with psychological and physical consequences such as anxiety, depression, headaches and increased blood pressure.

Given the pervasive and on-going nature of gender discrimination, a key factor in understanding these negative outcomes may be based in approaches that view coping as a process versus a one-time event (Folkman, Lazarus, Dunkel-Schetter, DeLongis \& Gruen, 1986; Folkman \& Lazarus, 1985; Lazarus, 1993; Lazarus \& Folkman 1984). The process approach to coping states that our responses to stress are less a function of the actual stressor than of the appraisals of the stressor (i.e., how severe, threatening or pervasive etc. is the stressor) and our strategies to cope (e.g., problem solving, social support etc.). However, because the stressor itself changes with the environment, the coping process (i.e., the appraisals and strategies) will also change with time (e.g., Lazarus \& Folkman, 1984). For instance, upon first experiencing a stressor, it may be appraised as severe (e.g., getting harassed). If a chosen strategy is effective at alleviating some distress (e.g., filing a complaint), the stressor may be re-appraised as less severe and a new strategy (e.g., cognitive restructuring-"I learned from the experience") may be used as the process continues. Alternatively, if the strategy is not successful at alleviating some distress, the situation may be re-appraised as even more overwhelming and another strategy may be chosen (e.g., giving up) in response to the new appraisal. Either way, this highlights what Lazarus and Folkman (1984) refer to as the transactional (or bidirectional) nature of the process, 
whereby a predictor at one point of the process (e.g., appraisal) can become an outcome at another part of the process. As such, the changing nature of these relationships means that a strategy or appraisal may be beneficial to well-being at one point in the process, but not as helpful at a different point (Lazarus \& Folkman, 1984; Schwarzer \& Schwarzer, 1996). Given how dynamic this process is then, Lazarus and Folkman (1984) argue that to gain a comprehensive understanding, coping is best observed over time so that these changing relationships can be captured.

However, most research on coping with discrimination does not acknowledge the role of time and process. Instead, the experiences and effects of discrimination are most often examined in experimental paradigms, whereby a lab simulation of discrimination is portrayed to participants (Foster, 2001; Foster \& Tsarfati, 2005; Kaiser, Major \& McCoy, 2004; Mallet \& Swim, 2005; McCoy \& Major, 2003; Schmitt, Branscombe \& Postmes, 2003) or it is examined at one point in time with questionnaires (e.g., Branscombe et al., 1999; Clark, 2006; Eccleston \& Major, 2006; Foster, 2000; Lightsey \& Barnes, 2007; Kaiser \& Miller, 2004; Peters, 2006; Schmitt, Branscombe, Kobrynowicz \& Owen, 2002; Scott \& House, 2005). Indeed, such methodologies are important for clarifying causation and how the recall of past events can currently affect us. Nevertheless, most research on discrimination gives little empirical attention to the role of time and process. The purpose of the current study therefore, was to examine how appraisals and coping strategies predict well-being across two points in time.

Appraisals. Within social psychology, there has been disagreement as to how those appraisals of discrimination will affect psychological outcomes. Some research in the U.S. has supported the discounting principle; when individuals appraise negative feedback as being due to 
discrimination (versus being caused by some other external event), self-esteem is protected because the victims of discrimination can discount their own role in the failure and instead blame an external source (e.g., a prejudiced perpetrator) (Crocker \& Major, 1989; Major, Kaiser \& McCoy, 2003; Eccleston \& Major, 2006). Alternatively, research supporting the rejection identification model (RIM; Branscombe, Schmitt \& Harvey, 1999) has found that when discrimination is appraised as pervasive across time and contexts it is associated with negative psychological consequences, namely decreased life satisfaction, personal self-esteem, positive affect, as well as increased anxiety and depression both in Canada (Foster \& Dion, 2003; Foster, Jackson, Hartmann \& Woulfe, 2004) and the U. S. (Branscombe, et al., 1999; Romero \& Roberts, 2003; Schmitt, et al., 2002; Schmitt, et al., 2003).

Researchers have suggested that one reason for this discrepancy is the way an appraisal of discrimination has been defined. In particular, in situations where the discrimination is considered to be a function of a biassed individual, victims of the discrimination may not show negative psychological outcomes because they can blame the negative outcome on the perpetrator rather than themselves (Major, Quinton \& Schmader, 2001; Schmitt et al., 2003). In contrast, when discrimination itself is appraised as pervasive in time and across contexts, it is more difficult to blame a particular individual. However, given that pervasive discrimination "implies future rejection" (Schmitt et al., 2003, p. 308) it is possible that blaming the perpetrator may still have negative psychological consequences if victims of discrimination expect the perpetrator to be prejudiced again in the future. Thus, consistent with RIM (Branscombe et al., 1999; Schmitt et al., 2003), I examined appraisals of pervasiveness that included perceiving the 
discrimination as pervasive across time and contexts, as well as the belief that the perpetrator would be biassed in the future.

Coping strategies. While social psychological research has acknowledged the role of appraisals of discrimination in well-being, the impact of coping strategies has been less broadly examined. Instead, studies have focussed on one coping strategy in particular, namely group identity (Branscombe et al., 1999; Eccleston \& Major, 2006; Major et al., 2003; Schmitt et al., 2002). A strong group identity can ameliorate the negative impact of appraisals of discrimination on psychological outcomes (e.g., Branscombe et al., 1999). However, given the wide range of coping strategies in the stress and coping literature (e.g., Lazarus \& Folkman, 1984), the current study examined alternative coping strategies, namely specific strategies used to respond to an instance of discrimination. To understand how appraisals of discrimination may interact with such strategies over time, I incorporated theories of discrimination that are based in disciplines such as sociology and women's studies. In particular, "stage" theories of political consciousness (Cross, 1978; Downing \& Rousch, 1985; Friere, 1973) are named for their explicit assumption that coping with discrimination occurs in stages over time, and as such are consistent with Lazarus and Folkman's (1984) dynamic perspective on coping. For example, the initial stage in the development of a gender consciousness often involves a recognition of discrimination as pervasive; some series of crisis events have occurred in a way that encourages women to realize that discrimination can occur repeatedly and in many facets of life (Downing \& Rousch, 1985). Appraising discrimination as pervasive often promotes an acceptance of discrimination; victims are so overwhelmed they accept discrimination as "the way things are." Consequently, they are said to report decreased well-being; victims are said to experience fear, 
anxiety and depression because victims of gender discrimination feel betrayed by the societal institutions in which they tried to participate (e.g., Bowles \& Duelli Klein, 1983; Downing \& Rousch, 1985; Driefus, 1973; Fischer \& Good, 2004; Jaggar, 1989).

However, as time progresses, recognizing the pervasiveness of discrimination is said to become motivating (e.g., Bowles \& Duelli Klein, 1983). The more women recognize that discrimination is a long-term problem and can affect them in any aspect of their life, the more they recognize that women's historical and political status can affect them personally. As such, the need for active responses to change women's status becomes more strongly supported. In turn, the combination of perceiving discrimination as pervasive but also acting out against it is said to enhance feelings of empowerment (Bartky, 1977; Carey, 1980; Driefus, 1973). While these theories have been developed primarily in the U.S., there is some evidence showing that women who perceive women to be pervasive act out against discrimination (Foster, 2001). Thus, while recognizing discrimination as pervasive is initially an overwhelming experience associated with acceptance and inactivity, it can ultimately combine with active strategies for combating discrimination, thereby enhancing well-being.

Given that stage theories (e.g., Downing \& Rousch, 1985), consistent with Lazarus \& Folkman (1984) suggest that at different points in the process, appraisals and coping strategies may combine differently to predict different well-being outcomes, the current study therefore examined how pervasiveness appraisals and active and inactive coping strategies would predict women's discrimination-related well-being. Canadian undergraduate women were exposed to a laboratory simulation of discrimination, whereby an experimenter gave them false negative feedback that was attributed to their gender. Participants were then assessed on their subsequent 
appraisals, coping strategies and well-being. One year later participants completed an online survey of their well-being. Consistent with Diener's (1998) definition of subjective well-being, well-being was measured in terms of mood, self-esteem and physical symptoms.

Hypotheses. As stage theories (e.g., Downing \& Rousch, 1985) suggest active coping responses do not develop until later in the process of consciousness-raising. One reason for this may be that victims of discrimination have not yet had the time to process meaning from their experiences (Downing \& Rousch, 1985) or acquire the necessary psycho-social resources necessary to actively combat discrimination (e.g., McCarthy \& Zald, 1977). For example, research has shown that the benefits of active coping with discrimination on well-being are diminished among less acculturated ethnic minority group members, i.e., among those without the psycho-social resources to adapt to cultural difficulties (Noh \& Kaspar, 2003). Thus, if utilized too early in the process, active coping may serve as an additional stressor, decreasing well-being. It was therefore expected that

Hypothesis 1a: Immediately after the discrimination occurred, pervasiveness appraisals would interact with active coping strategies to predict well-being, such that increased active coping would be related to decreased well-being and this relationship would be strongest among those making high pervasiveness appraisals.

In contrast, inactive strategies may provide victims of gender discrimination with more time to process and understand their experience or gain the necessary resources, thereby serving to decrease their stress. Indeed, secondary control strategies (i.e., control over one's own reaction) are often more helpful than primary control strategies (control over the stressor) in 
situations when the stressor is uncontrollable (e.g., Helgeson, 1992; Rothbaum, Weisz \& Snyder, 1982). Research has also shown that for some victims of discrimination passive strategies can diminish discrimination-related depression (Noh, Beiser, Kaspar, Hou \& Rummens, 1999). Thus, it was also expected that

Hypothesis 1b: Immediately after the discrimination occurred, pervasiveness appraisals would interact with inactive coping strategies to predict well-being such that increased inactive coping would be related to increased well-being, and this relationship would be strongest among those making high pervasiveness appraisals.

Over time however, being active may be less likely to serve as an additional stressor. Consistent with stage theories (Downing \& Rousch, 1985), victims come to better understand their experiences, develop additional resources and skills and come to feel empowered by actively combatting discrimination. As such, being active may instead enhance well-being. It was therefore expected that

Hypothesis 2a: One year later, pervasiveness appraisals would interact with active coping strategies to predict well-being such that increased active coping would be related to increased well-being, and this relationship would be strongest among those making high pervasiveness appraisals .

In contrast, inactive strategies may ultimately enhance stress because they maintain the status quo, enhancing the likelihood that the stressor, namely gender discrimination, will recur. Indeed, recurring uncontrollable stressors can lead to learned helplessness (Seligman, 1975). Not only that, certain inactive strategies such as keeping emotions inside have been related to 
decreased well-being (Matheson \& Anisman, 2003; Pennebaker \& Chung, 2007). Thus, it is also expected that

Hypothesis $2 b$. One year later, pervasiveness appraisals would interact with inactive coping strategies to predict well-being such that increased inactive coping would be related to decreased well-being, and this relationship would be strongest among those making high pervasiveness appraisals.

\section{Method}

\section{Participants}

The initial sample included 73 female introductory psychology students $\left(M_{\text {age }}=19\right.$ years, $S D=1.95)$ at Wilfrid Laurier University in Waterloo, Ontario, Canada who participated in the study for course credit. Reported ethnicity was $69.1 \%$ White European descent, $5.2 \%$ East Asian, 3.9\% South Asian, 3.9\%, Black, 2.6\% Latin, 2.6\% reported being part of a religious minority, and $12.7 \%$ did not report their ethnicity. However, only 31 participated in the followup $\left(M_{\mathrm{age}}=18\right.$ years, $\left.S D=1.0\right)$. Reported ethnicity for the final sample was: $78 \%$ White European descent, 6\% South Asian and 16\% unknown. Men were included in the experiment because past research has shown the portrayal of discrimination is more realistic when men are present (Foster, 2001; Foster, Matheson, \& Poole, 1994). However, because men were defined as being advantaged, they leave the experiment before dependent measures are collected. Thus, they were not included in the analyses.

\section{Procedure}


Participants came to the lab in groups of six (four female, two male) and a female experimenter (Experimenter 1) gave an overview of what the experiment would entail. In reality, that overview was a cover story designed to conceal the purpose of the study. Specifically, participants were told that this was an experiment in a program of studies investigating testtaking anxiety. To assess how their anxiety might be related to test performance, they would first complete a sample task similar to the Graduate Record Examination, namely five multiple choice questions in $5 \mathrm{~min}$. After completion of the questions, their scores would be assessed by another experimenter. Allegedly, only the highest scoring participants would then be selected to enter what was called the "video group." The other participants would remain behind to participate in a second part of the experiment.

The purpose of these group delineations was to simulate a hierarchical intergroup situation (Foster, 2001; Foster et al., 1994; Wright, Taylor \& Moghaddam, 1990). The methodological goal was to establish a group that participants would aspire to be in and where inclusion would reflect personal success and high social value. The second group should represent a relative lack of success and low social value. This differential evaluation of the two groups was achieved by varying the mundaneness of the task and the rewards associated with the work performed. Supposedly, those who performed well on the test would be asked to participate in the development of a video for students, which might help to decrease the anxiety associated with test-taking. They were told they would do this in a different experimental room where refreshments would be served and that they would be eligible for a $\$ 200$ lottery. Thus, their skills were valued by the experimenter and they could potentially receive a large reward. In contrast, those who did not perform well on the test would continue to complete a series of other 
tests that would assess whether their low performance generalizes to other types of skills such as math. Also, they would only be eligible for a $\$ 10$ lottery. Thus, their continuation in the experiment would be tedious, their skills less valued by the experimenter, and only a small reward could potentially be received. The task and scoring were actually bogus and all participants were eligible for the $\$ 200$ lottery.

Participants also were told that a second experimenter (Experimenter 2), chosen as a research assistant because he had previously been a successful participant in this study, would observe their body language while they were completing the sample GRE test. It was explained that various body language indicators of test anxiety would be combined with their GRE test scores to create an overall score, which would determine whether they would proceed to the video group or remain behind. This observation was also bogus.

The potential for gender discrimination was then made salient by Experimenter 1: I should warn you that this task and the way it is scored could be considered to be discriminatory against women. It seems that women don't do well on this task and so it is very rare that women are allowed into the video group, while men almost always get in. We can talk about this after the experiment if you like, but we do have time limitations for this experiment, so we should continue.

Participants were then given 5 min to complete their sample GRE test, which was then collected and ostensibly scored. Experimenter 2 calculated the overall test anxiety scores. After the scoring, discrimination was perpetrated via false feedback such that Experimenter 2 told participants that only women received a failing score, whereas all the men received a passing score. Those who passed were then asked to accompany Experimenter 2 to a different room 
where they would presumably participate in the video development, but they were actually debriefed. As such, it appeared to participants that consistent with the experimenter's previous warning, only men received the necessary passing score.

After the successful participants (i.e., men) had left, the women remained to complete a questionnaire presumably designed to assess their opinions on the use of the task but actually contained the manipulation check and dependent measures. Once they had completed the questionnaire, they were told that there was no second part of the experiment and were then given an oral and written debriefing. This debriefing was given to both women and men. It included a detailed, four-page description of the purpose of the study; an explanation as to why deception was necessary to examine the purpose; repeated confirmation that their performance was not actually measured; as well as a contact sheet with phone numbers of local resources (e.g., counseling centers). Discussions after debriefing indicated that participants understand the need for deception to obtain spontaneous reactions and no adverse reactions have been reported (Foster, 1999, 2001; Foster et al., 1994).

One year later, participants were contacted to participate in an online study described as a variety of personal and social opinion questions. They were sent a web address where they could complete a 30 minute questionnaire containing measures of well-being.

\section{Lab Measures}

\section{Manipulation check.}

To assess whether gender discrimination was adequately portrayed, participants read that "ethical guidelines require that we ask several questions." Using a scale ranging from "not at all" 
(0) to "extremely" (4), they indicated "How fairly were you personally treated, due to your gender in the present experiment?" Lower scores represented greater perceived unfairness. Pervasiveness appraisals.

To assess pervasiveness of the discrimination itself, participants responded to two items using a scale ranging from "not at all" (0) to "extremely" (4): "Would today's experience be likely to happen again in the future" (time-pervasiveness) and "Would today's experience be likely to affect other areas of your life, or happen in other situations" (context-pervasiveness). These items were averaged for an overall pervasiveness of discrimination score (Cronbach $\alpha=$ $.75)$.

The operational definition of pervasiveness was further expanded to include the perpetrator's behaviour. Schmitt and Branscombe (2002) have noted that people's definition of discrimination includes an attribution to the prejudiced person i.e., not only can discrimination occur because of group membership, but also because of the prejudice person. Thus, to assess the pervasive nature of the experimenter's bias a third item was included: "How likely is it that the experimenter will be biassed again in the future." This item was analysed separately as it was unrelated to the other pervasiveness items (see Table 2).

Coping strategies.

In an attempt to use items that are particularly relevant to students within the context of this experimental paradigm, active and inactive strategies were chosen from two different sources, namely Matheson and Anisman's (1993) Survey of Coping Profile Endorsement (SCOPE) and strategies specific to this experimental paradigm that were derived from Wright, et al. (1990). Active strategies are defined as those strategies aimed at changing the stressor itself 
(Carver et al., 1989; Lazarus \& Folkman, 1989). Using a scale that ranged from "not at all” (0) to "extremely" (4), participants indicated how they felt like behaving at that moment in response to four items from Wrigth et al. (1990): "Request an individual retest of your score"; "Confront the experimenter and demand an explanation of your particular group assignment": "Ask that the group be retested on their scores"; "Get together with other students to confront the experimenter, demanding an explanation for your group assignment. The items were averaged for an overall active coping score (Cronbach $\alpha=.89)$.

Inactive strategies, which are often considered emotion-focused (i.e., aimed at regulating the emotional reaction to the stressor), can be defined as the absence of action (Carver et al., 1989). To that end, inactive coping was also measured with two sub-scales: emotional containment and acceptance. Using the same rating scale, participants indicated how they felt like behaving at that moment in response to two items assessing emotional containment ("holding in my feelings"; "just acting as if I'm not upset"). These items were derived from the SCOPE (Matheson \& Anisman, 1993) and averaged for an overall score (Cronbach $\alpha=.73$ ). An individual item from Wright et al. (1990) assessed acceptance of discrimination ("accept the situation, that is, your assignment to either group, as is").

Well-being.

After indicating their preferred strategies, participants completed measures of mood and self-esteem, consistent with Diener's (1998) conceptualization of subjective well-being.

Mood. A mood checklist previously developed for this experimental paradigm (Foster \& Dion, 2003) contained six adjectives that were combined to represent negative affect (distressed, nervous, sad, helpless, hesitant, and uncertain; Cronbach $\alpha=.77)$. Using a scale ranging from 
"not at all" (0) to "extremely" (4) participants indicated the extent to which they felt each adjective at the present moment.

Self-esteem. The performance sub-scale from Heatherton and Polivy's (1991) state selfesteem scale was used. Using a scale ranging from "not at all" (0) to "extremely" (4), participants rated eight items, indicating what is true for them right now (e.g., "I feel confident about my abilities", "I am worried about whether I am regarded as a success or failure.") The mean score across the three items was used as the overall score (Cronbach's $\alpha=.84$ ). High scores represented high self-esteem.

\section{Followup well-being measures}

Mood. Participants indicated what percent of the time they feel unhappy (Fordyce, 1988).

Self-esteem. The interpersonal sensitivity subscale from the Hopkins Symptom Checklist (Derogatis, Lipman, Rickels, Ulenhuth, \& Covi, 1974), which assesses self-esteem (e.g., "feeling inferior to others", "feeling that people are unfriendly or dislike you"; Cronbach $\alpha$ $=.84$ ) was used. Using a scale ranging from "not at all" (0) to "extremely" (3), participants indicated the extent to which they had been bothered by various symptoms over the past week. The mean was used as the overall score. Scoring was reversed so that high scores represented high self-esteem.

Physical symptoms. Finally, as a non-subjective measure of well-being, the somatization sub-scale of the Hopkins Symptom Checklist (Derogatis et al., 1974) was also used. It assesses physical symptoms experienced over the past week. (e.g., "headaches", "soreness of your muscles"; Cronbach $\alpha=.82$ ). The mean was used as the overall score. 
Coping with discrimination over time

Results

\section{Descriptive Statistics}

Table 1 contains means and standard deviations for all measures. Participants considered the pervasiveness of the discrimination and experimenter's bias to be similar, $\mathrm{t}(25)=-.08, \mathrm{p}=$ .93. Consistent with past research (e.g., Foster, in press; Gill \& Matheson, 2006), accepting discrimination was the most commonly endorsed coping strategy, more so than both emotional containment, $t(29)=3.56, p=.001$ and active coping, $t(29)=3.92, p=.0001$. Emotional containment and active coping were equally endorsed, $t(29)-1.41, p=.17$

\section{Analyses}

To test how pervasiveness appraisals and intended strategies to cope with an experience of discrimination would interact to predict well-being at that time and one year later, several sets of hierarchical regression analyses were conducted. Each appraisal (pervasiveness of the discrimination and the experimenter's bias) and its interaction with each coping strategy (action, acceptance, emotional containment) was examined in a separate regression. Well-being measures at each assessment time were regressed onto centred scores for the main effects (appraisals and strategies) on the first step, and their product term on the second step. Tests of the simple slopes were conducted as suggested by Aiken and West (1990). Tests of multicollinearity indicated that assumptions were met. Inter-correlations appear in Table 2. Regressions are summarized in Table 3. Significant interactions are described below. For comparison purposes, analyses were conducted on those completing both waves of data $(\mathrm{n}=31)$.

\section{Lab Discrimination Analyses (Time 1)}


Manipulation Check. For the manipulation of discrimination to have been successful, women would need to score at the low end of the scale, indicating perceived unfairness. A onesample t-test was used to test scores against the midpoint of the scale (Tabachnick \& Fidell, 2007). Participants' average score was $1.23(S D=1.35)$, and was significantly lower than the midpoint of the scale, $t(29)=-3.10, p=.004$. Thus, women perceived the unfair treatment toward their gender that was portrayed.

Hypothesis 1a. To test the interaction between pervasiveness appraisals and active coping on well-being, pervasiveness of discrimination and active coping were entered onto the first step of a regression, and their product term was entered onto the second. The main effects predicted $38.7 \%$ of the variability in negative affect, $F(2,27)=8.51, p=.001$, such that both increased pervasiveness and increased action were uniquely related to greater negative affect (see Table 3). A significant interaction predicted an additional $29.6 \%$ of the variance, $F(1,26)=$ 24.18, $p=.0001$. As predicted, increased endorsement of action predicted increased negative affect among those perceiving highly pervasive discrimination, $\beta=.63, p=.0001$. The simple slope for low pervasiveness was not significant, $\beta=-.20, p=.23$.

Similarly, pervasiveness of the experimenter's bias and active coping were entered onto the first step and their product term was entered onto the second step of a second hierarchical regression. The main effects marginally predicted negative affect, $F(2,23)=3.03, p=.06$, with only increased action marginally related to increased negative affect (see Table 3). There was a significant interaction between experimenter bias and action, predicting $13 \%$ of the variability in negative affect, $F(1,22)=4.34, p=.049$. As predicted, increased endorsement of action was associated with greater negative affect among those perceiving future experimenter bias, $\beta=.59$, 
$p=.012$. The relationship between active coping and affect was not significant among those perceiving little bias from the experimenter in the future, $\beta=-.34, p=.40$.

Hypothesis $1 b$. To test the interaction between pervasive appraisals and inactive coping on well-being, pervasiveness of discrimination and emotional containment were entered on the first step, and their product term was entered onto the second step of a hierarchical regression. The main effects significantly predicted $44.6 \%$ of the variability in negative affect, $F(2,27)=$ $10.86, p=.0001$ such that increased pervasiveness of discrimination and emotional containment were related both uniquely related to increased negative affect (see Table 3). A significant interaction predicted an additional $38.9 \%$ of the variability in negative affect, $F(1,26)=61.51, p$ $=.0001$. Increased emotional containment was associated with increased negative affect, $\beta=.67$, $\mathrm{p}=.001$ among those perceiving highly pervasive discrimination. The simple slope for low pervasiveness was marginally significant, $\beta=-.24, p=.06$ indicating that increased emotional containment was related to decreased negative affect among those who perceived the situation to be isolated.

Similarly, pervasiveness of the experimenter's bias and emotional containment and their product term were onto the first and second steps respectively of a regression. The main effects significantly predicted $37.2 \%$ of the variability in negative affect, $F(2,23)=6.82, p=.005$ such that only increased emotional containment was associated with increased negative affect (see Table 3). The interaction predicted an additional $17.9 \%$ of variability in negative affect, $F(1,22)$ $=8.80, p=.007$. Increased emotional containment was associated with increased negative affect, $\beta=.86, p=.0001$ among those perceiving future experimenter bias. The simple slope for those perceiving little experimenter bias in the future was not significant, $\beta=.03, p=.90$. 
Finally, pervasiveness of discrimination and acceptance were entered onto the first step and their product term was entered onto the second step of another regression. The main effects predicted $21.8 \%$ of the variability in self-esteem, $F(2,27)=3.76, p=.036$ with only increased pervasiveness marginally related to decreased self-esteem (see Table 3). The interaction marginally predicted an additional $9.6 \%$ of the variability in self-esteem, $F(1,26)=3.65, p=.06$. Although the simple slope for high pervasiveness was not significant, $\beta=-.11, p=.66$, increased acceptance was related to increased self-esteem among those perceiving the discrimination to be isolated, $\beta=.56, p=.02$.

These findings were replicated when conducted on the full Time 1 sample $(\mathrm{N}=73)$ as well.

\section{Followup Analyses (Time 2)}

Hypothesis $2 a$. To test the interaction between pervasiveness appraisals and active coping on well-being one year later, each pervasiveness appraisal (pervasiveness of the discrimination and the experimenter's bias) and its interaction with active coping was entered into a separate regression (see Table 3). Although perceiving pervasive experimenter bias was related to increased unhappiness one year later (see Table 1), there were no significant interactions.

Hypothesis $2 b$. To test the interaction between pervasiveness appraisals and inactive coping on well-being one year later, pervasiveness of experimenter's bias and acceptance were entered onto the first step, and their product term was entered onto the second step of a hierarchical regression. The main effects marginally predicted $19.5 \%$ of the variance in unhappiness, $F(2,23)=2.78, p=.080$, with increased experimenter pervasiveness uniquely 
related to increased unhappiness (see Table 3). In addition, there was a significant interaction between experimenter pervasiveness and accepting the discrimination, $F(1,22)=5.55, p=.028$, explaining an additional $16.2 \%$ of the variability in unhappiness. As predicted, endorsing an acceptance of the discrimination was related to increased unhappiness one year later among those expecting future experimenter bias, $\beta=.85, p=.038$. There was no significant simple slope for those expecting little experimenter bias in the future, $\beta=-.10, p=.70$.

Similarly, in another regression analysis, experimenter bias and emotional containment were entered onto the first step and their product term was entered onto the second step. The main effects explained $26.6 \%$ of the variability in unhappiness, $F(2,23)=4.16, p=.03$, with only experimenter bias uniquely related to greater unhappiness (see Table 3). There was a significant interaction, $F(1,22)=4.42, p=.014$ explaining an additional $11 \%$ of the variability in unhappiness. As predicted, among those expecting future experimenter bias, the more participants endorsed keeping their feelings inside, the greater unhappiness they reported one year later, $\beta=.53, p=.02$. The simple slope for those expecting little experimenter bias in the future was not significant, $\beta=-.13, p=.63$.

Experimenter bias and emotional containment also marginally interacted to predict $13.6 \%$ and $14 \%$ of the variability in self-esteem one year later, $F(1,22)=4.2, p=.06$ as well as physical symptoms, $F(1,22)=3.7, p=.06$ respectively. Among those who thought the experimenter would be biassed in the future, keeping feelings inside was related to decreased self-esteem, $\beta=-.74, p=.04$ and increased physical symptoms, $\beta=.37, p=.06$ one year later. The simple slopes for those expecting little experimenter bias in the future were not significant, $\beta$ self-esteem $=.23, \mathrm{p}=.39, \beta_{\text {physical symptoms }}=.17, p=.54$. 


\section{Discussion}

Consistent with past research (Branscombe et al., 1999), perceived pervasiveness was related to negative affect at the time of the experiment and to unhappiness one year later, supporting the notion that appraising gender discrimination as pervasive is associated with negative psychological outcomes. More specifically, it was the pervasiveness of the discrimination that was related to negative affect immediately, whereas the pervasiveness of the experimenter's bias was related to unhappiness one year later. Similarly, while both measures of pervasiveness interacted with coping strategies to predict immediate negative affect, it was experimenter bias that significantly interacted with inactive strategies to predict well-being one year later. One explanation is that different dimensions of perceived pervasiveness may have different long-term implications. It may be that as an experimental paradigm participants knew they would not likely encounter again, the pervasiveness of the experience had little long-term effect. However, believing a perpetrator of discrimination will continue to be biassed may continue to be threatening, as that perpetrator may continue to be discriminatory to them and to others. Despite being debriefed, participants may have become more sensitive to discrimination, anticipating that there may indeed be other individuals who could also be biassed. Thus, the pervasiveness of the perpetrator's bias may be an important part of understanding how people cope with discrimination over the long run.

The impact of perceived pervasiveness on well-being was qualified by several interactions. Consistent with hypotheses, among those perceiving high pervasiveness active coping was initially related to decreased negative affect. This is interesting in that North American ideology promotes active responses, through cultural icons (e.g., the pioneer, the 
soldier) and colloquialisms (e.g., "When the going gets tough, the tough get going"). Moreover, research has shown that active coping can often promote well-being (e.g., Aldwin, 1994; Holman \& Silver, 2005; Treharne, Lyons, Booth \& Kitas, 2007). However, the combination of perceiving pervasive discrimination and wanting to do something about it may not necessarily be good for well-being upon first experiencing the stressor. If, as stage theories suggest (e.g., Downing \& Rousch, 1985), empowerment is not developed until later in the process, then taking action too early may cause distress. Participants may not have had enough time to process their experience (Downing \& Rousch, 1985), or to develop sufficient psycho-social resources (McCarthy \& Zald, 1977). Thus, in the current study intending to take action too early may have only exacerbated the psychological distress that accompanies perceiving pervasive discrimination.

Unexpectedly, active coping was no longer a significant predictor of well-being at follow-up. The pattern that action was associated with decreased well-being immediately and then became unrelated to well-being one year later may be a part of a learned response. Basic learning theory states that if a behaviour has positive consequences, it will be repeated, but a behaviour followed by negative consequences will be avoided (Skinner, 1971). If intending to taking action immediately worsens mood, then active strategies may likely be avoided in the future. In the current study, given participants felt badly after endorsing active coping, then it may not be a strong enough predictor of well-being in the future. Further, if women are learning not to take action because of its initial negative consequences, then the cycle of the status quo may not be surprising. Indeed, researchers often comment on the fact that minority group members, despite objective disadvantage, prefer to remain inactive, thereby contributing to their 
own disadvantage (McCarthy \& Zald, 1977; Runciman, 1966; Tajfel \& Turner, 1979; Taylor \& McKirnan, 1984). If discrimination is not actively combatted, then the unfair system remains the same. Thus, the low levels of activism among those who suffer disadvantage may be quite logical; if action hurts the first time, why bother again?

Consistent with hypotheses, the strategies that enhanced well-being initially were the inactive ones. Although this relationship was originally hypothesized for those perceiving high pervasiveness, increased acceptance and emotional containment were related to increased wellbeing among those perceiving low pervasiveness. The reason why inactive strategies were helpful for those perceiving low versus high pervasiveness may not be because of the time needed to process the experience as was hypothesized for those high in pervasiveness, but perhaps because inactivity is a strategy that is consistent with the appraisal. That is, doing nothing in response to an event appraised as isolated seems a logical response. Similarly, the reason inactive strategies may not have been beneficial for those high in pervasiveness may be because the strategies ("do nothing") are too inconsistent with the appraisal that discrimination "is everywhere". Perhaps those high in pervasiveness initially require strategies that are not too high risk in activity to promote additional stress, but not completely passive either. Such "middle ground" strategies may include those that provide them ways to make meaning of their experience while gaining the necessary psych-social resources to cope, such as venting, emotional support, or spirituality.

Also consistent with hypotheses was that inactivity was also related to decreased wellbeing one year later among those perceiving high pervasiveness. In fact, inactive coping appeared to grow in negative consequences in that not only was the negative mood affected, but 
self-esteem and physical symptoms were negatively affected one year later as well. Although the relationship to the latter was marginal, it is consistent with research on the negative consequences of emotional containment (e.g., Pennebaker \& Chung, 2007). Thus, while intending to be active may not have been an effective strategy upon first encountering a stressor, nor is a preference for accepting discrimination and keeping quiet about it, a healthy long-term solution.

\section{Limitations}

It could be argued that the change in patterns of relationships is speculative given the different measures of well-being that were used across the lab study and its followup. However, one challenge for researchers doing longitudinal research is to avoid the demand characteristics and practice effects that could occur as a function of using identical measures (e.g. Cook \& Campbell, 1979). Indeed, the experimental study was likely very memorable given its use of deception. Had participants recognized the follow-up measures there may have been a stronger likelihood of linking the purpose of the two studies. Given the potential risks of practice effects and such demand characteristics, a choice was made to use alternative, but conceptually similar measures at follow-up.

Another limitation was sample size, a common problem when conducting longitudinal research (e.g., Cook \& Campbell, 1979). Although the difficulty in finding significant interactions (McClelland \& Judd, 1993) may attest to the strength of these relationships, the small sample size may have limited external validity. For example, possible differences between white and visible minority women could not be tested given the sample distribution. At the same time however, the robustness of the personal/group discrimination discrepancy, whereby 
disadvantaged groups report more perceive group than personal discrimination, suggests that perceptions of discrimination are similar in a variety of ethnic, language, gender and sexual minorities (Birt \& Dion, 1987; Dion \& Kawakami, 1996; Taylor, Wright, Moghaddam \& Lalonde, 1990; Taylor, Wright \& Porter, 1993) in Canada and the US (Crosby, 1982; Crosby, 1984; Crosby, Pufall, Snyder, O’Connell \& Whalen, 1989; D’Emilio, 1983; Operario, \& Fiske, 2001), not to mention outside North America (Bourguignon, Seron, Yzerbty \& Herman, 2006; Verkuyten, 2002; Verkuyten \&Nekuee, 2001). Further, the negative physical and psychological responses to discrimination have also been shown to be similar across Canadian (Foster, 2000; Foster \& Dion, 2003; Matheson, Gill, Kelly \& Anisman, 2008) and American samples (Branscombe, Schmitt \& Harvey, 1999; Krieger \& Stanley, 1996; Landrine, Klonoff, Corral, Fernandez, \& Roesch, 2006; Landrine, Klonoff, Gibbs, Manning \& Lund, 1995) as well as countries outside of North America (Bourguignon et al., 2006; Resersdorff, Martinot \& Branscombe, 2004). Thus, the applicability and interest of these findings to a variety of groups is likely. Moreover, although participants in the current study were Canadian and much of the reviewed literature involves American data, there was no expectation that Canadian women's reactions to discrimination would differ from women in other countries, given the cross-cultural similarity in perceptions about discrimination. Future research will nevertheless need to increase the sample size to test for additional similarities and possible differences.

Finally, it may be that in order to understand a "process", measurements at more than two points in time are necessary. On the one hand, because there is a lack of longitudinal research in the area of coping with discrimination, this study does provide an important beginning contribution. Nevertheless, more frequent time assessments may provide a better understanding 
of the transactional nature of coping with discrimination. As such, research in my lab is currently conducting daily diary studies to understand how coping strategies may affect daily variations in well-being. Such data may suggest how strategies affect well-being and in turn, how daily changes in well-being may alter coping strategies. Indeed, while the order in which measures were given in the current study (i.e.., coping strategies preceded well-being measures) suggests that coping affected well-being, it is also consistent with the dynamic nature of the coping process (Lazarus \& Folkman, 1984) that compromised well-being could have affected coping strategies.

Diary research may also help to assess the difference between the consequences of preferred and enacted coping strategies. In the current study, participants did not have the opportunity to use their indicated preferred strategies, yet in a diary study participants can be asked "how did you cope today?" It is possible that actually enacting a strategy may have different long term consequences than when it is endorsed.

Despite limitations, this study suggests that time has a role to play in understanding how victims of discrimination cope. Whether time "heals all wounds" however, may indeed depend on the coping strategy. Although active coping may not be immediately healing, if inactive coping is used over a long period of time, the psychological effects may be detrimental. 
Coping with discrimination over time

\section{References}

Aiken, L. S., \& West, S. G. (1991). Multiple regression: Testing and interpreting interactions. Thousand Oaks, CA: Sage.

Aldwin, C. M. (1994). Stress, coping and development. New York: Guilford Press.

Allison, K. W. (1998). Stress and oppressed category membership. In J. K. Swim \& C. Stangor (Eds.), Prejudice: The target's perspective (pp. 145-170). San Diego, CA: Academic Press.

Bartky, S. L. (1977) Toward a phenomenology of feminist consciousness. In M. VetterlingBraggin, F. Elliston, \& J. English (Eds.), Feminism and philosophy (pp. 22-37). Totawa, NJ: Littlefield.

Birt, C. M., \& Dion, K. L. (1987). Relative deprivation theory andresponses to discrimination in a gay male and lesbian sample. British Journal of Social Psychology, 26, 139-145.

Bowles, G., \& Klein, R. D. (1983). Theories of women's studies. London: Routledge.

Bourguignon, D., Seron, E., Yzerbyt, V., \& Herman, G. (2006). Perceived group and personal discrimination: Differential effects on personal self-esteem. European Journal of Social Psychology, 36, 773-779.

Branscombe, N. R., Schmitt, M. T. \& Harvey, R. D. (1999). Perceiving pervasive discrimination among African-Americans: Implications for group identification and well-being, Journal of Personality and Social Psychology, 77, 135-149.

Carey, P. (1980). Personal is political. Canadian Women's Studies, 2, 4-7. 
Carver, C. S. (1997). You want to measure coping but your protocol's too long: Consider the brief COPE. International Journal of Behavioral Medicine, 4, 92-100.

Carver, C. S., Scheier, M. F., \& Weintraub, J. K. (1989). Assessing coping strategies: A theoretically based approach. Journal of Personality and Social Psychology, 56, 267283.

Clark, R. (2006). Interactive but Not Direct Effects of Perceived Racism and Trait Anger Predict Resting Systolic and Diastolic Blood Pressure in Black Adolescents. Health Psychology, 25, 580-585.

Cook, T. D., \& Campbell, D. T. (1979). Quasi-experimentation: Design and analysis for field settings. Chicago, IL: Rand McNally.

Crocker, J., \& Major, B. (1989). Social stigma and self-esteem: The self-protective properties of stigma. Psychological Review, 96, 608-630.

Crosby, F. J. (1982). Relative deprivation and working women. New York: Oxford University Press.

Crosby, F. J. (1984). The denial of personal discrimination. American Behavioral Scientist, 27, 371-386.

Crosby, F. J., Pufall, A., Snyder, R., O'Connell, M., \& Whalen, P. (1989).The denial of personal disadvantage among you, me, and all the other ostriches. In M. Crawford \& M. Gentry (Eds.), Gender and thought (pp. 79-99). New York: Springer-Verlag.

Cross, W. E., Jr. (1978). The Thomas and Cross models of psychological nigrescence: A review. Journal of Black Psychology, 5, 13-31. 
Coping with discrimination over time

Degarmo, D. S., \& Martinez, C. R. Jr., (2006). A culturally informed model of academic wellbeing for Latino youth: The importance of discriminatory experiences and social support. Family Relations, 55, 267-278.

D’Emilio, J. (1983). Sexual politics, sexual communities: The making of a homosexual minority in the U.S., 1940-1970. Chicago: University of Chicago Press.

Derogatis, L.R., Lipman, R.S., Rickels, K., Uhlenhuth, E.H., \& Covi, L. (1974). The Hopkins Symptom Checklist (HSCL): a self-report symptom inventory. Behavioral Science, 19, 1-15.

Diener, E. (1998). Subjective well-being and personality. In D. F. Barone, \& M. Hersen (Eds). Advanced personality. The Plenum series in social/clinical psychology (pp. 311-334). New York, NY: Plenum Press

Dion, K. L., \& Earn, B. M. (1975). The phenomenology of being a target of prejudice. Journal of Personality and Social Psychology, 32, 944-950.

Dion, K. L., \& Kawakami, K. (1996). Ethnicity and perceived discrimination in Toronto: Another look at the personal/group discrimination discrepancy. Canadian Journal of Behavioural Science, 28, 203-213.

Downing, N. E., \& Rousch, K. L. (1985). From passive acceptance to active commitment:A model of feminist identity development for women. The Counseling Psychologist, 13, 695-709.

Driefus, C. (1973). Women's fate: Rap from a feminist consciousness-raising group. New York: Bantam. 
Coping with discrimination over time

Eccleston, C. P., \& Major, B. N. (2006). Attributions to discrimination and self-esteem: The role of group identification and appraisals. Group Processes and Intergroup Relations, 9, $147-162$.

Fischer, A. R., \& Good, G. E. (2004). Women's feminist consciousness, anger and psychological distress. Journal of Counseling Psychology, 51, 437-446.

Folkman, S., \& Lazarus, R. S. (1985). If it changes it must be a process: Study of emotion and coping during three stages of a college examination. Journal of Personality and Social Psychology, 48, 150-170.

Folkman, S., Lazarus, R. S., Dunkel-Schetter, C., DeLongis, A., \& Gruen, R. J. (1986).

Dynamics of a stressful encounter: Cognitive appraisal, coping, and encounter outcomes. Journal of Personality and Social Psychology, 50, 992-1003.

Fordyce, M. W. (1988). A review of research on the happiness measures: A sixty second index of happiness and mental health. Social Indicators Research, 20, 355-381.

Foster, M. D. (1999). Acting out against discrimination: The effects of different social identities. Sex Roles, 40, 167-186.

Foster, M. D. (2000). Positive and negative responses to personal discrimination: Does coping make a difference? Journal of Social Psychology, 140, 93-106.

Foster, M. D. (2001). The motivational quality of global attributions in hypothetical and experienced situations of gender discrimination. Psychology of Women Quarterly, 25, 242-253. 
Coping with discrimination over time

Foster, M. D. (2007, January). The immediate and long-term effects of a lab simulation of discrimination on well-being. Poster presented at the Society of Social and Personality Psychology Annual Convention. Memphis, Tennessee.

Foster, M. D. \& Dion, K. L. (2003). Dispositional hardiness and women's well-being relating to gender discrimination: The role of minimization. Psychology of Women Quarterly, 27, 197-208.

Foster, M. D., Jackson, C. L., Hartmann, R., \& Woulfe, S. (2004).Minimizing the pervasiveness of women's personal experiences of gender discrimination, Psychology of Women Quarterly, 28, 224-232.

Foster, M. D. \& Matheson, K. \& Poole, M. (1994). Responding to sexual discrimination: The effects of societal versus self-blame. Journal of Social Psychology, 134, 743-754.

Foster, M. D. \& Tsarfati, E. M. (2005). The motivational quality of shattered assumptions when responding to an acute experience of gender discrimination. Personality and Social Psychology Bulletin, 31, 1730-1738.

Friere, P. (1973). Education for critical consciousness. New York: Seabury.

Gill, R., \& Matheson, K. (2006). Responses to discrimination: The role of emotion and expectations for emotional regulation. Personality and Social Psychology Review, 32, 149-161.

Gutierrez, L. M. (1990). Working with women of colour: An empowerment perspective. Social Work, 35, 149-153.

Heatherton, T. F., \& Polivy, J. (1991). Development and validation of a scale for measuring state self-esteem. Journal of Personality and Social Psychology, 60, 895-910. 
Helgeson, V. S. (1992). Moderators of the relation between perceived control and adjustment to chronic illness. Journal of Personality and Social Psychology, 63, 656-666.

Holman, E. A., \& Silver, R. C. (2005). Future-oriented thinking and adjustment in a nationwide longitudinal student following the September $11^{\text {th }}$ terrorist attacks. Motivation and Emotion, 29, 389-410.

Jaggar, A. M. (1989). Love and knowledge: emotion in feminist epistemology. In A.M. Jaggar and S. R. Bordo (Eds.), Gender/body/knowledge: Feminist reconstructions of being and knowing (pp. 145-171). New Brunswick, NJ: Rutgers University Press.

Janoff-Bulman, R. (1989). Assumptive worlds and the stress of traumatic events: Applications of the schema construct. Social Cognition, 7, 113-136.

Kaiser, C. R., Major, B., \& McCoy, S. K. (2004). Expectations about the future and the emotional consequences of perceiving prejudice. Personality \& Social Psychology Bulletin, 30, 173-184.

Kaiser, C. R., \& Miller, C. T. (2004). A stress and coping perspective on confronting abstract sexism. Psychology of Women Quarterly, 28, 168-178.

Klonoff, E. A., Landrine, H., \& Campbell, R. (2000). Sexist discrimination may account for well-known gender differences in psychiatric symptoms. Psychology of Women Quarterly, 24, 93-99.

Krieger, N. (1990). Racial and gender discrimination: Risk factors for high blood pressure?

Krieger, N. \& Stanley, S. (1996). Racial discrimination and blood pressure: The CARDIA study of young black and white adults. American Journal of Public Health, 86, 1370-1378.

Landrine, H., Klonoff, E. A., Corral, I., Fernandez, S., \& Roesch, S. (2006). Conceptualizing and 
Coping with discrimination over time

measuring ethnic discrimination in health research. Journal of Behavioral Medicine, 29, 79-94.

Landrine, H., Klonoff, E. A., Gibbs, J., Manning, V., \& Lund, M. (1995). Physical and psychiatric correlates of gender discrimination: An application of the schedule of sexist events. Psychology of Women Quarterly, 19, 473-492.

Lazarus, R. S. (1993). Coping theory and research: Past, present and future. Psychosomatic Medicine, 55, 234-247.

Lazarus, R. S., \& Folkman, S. (1984). Stress, appraisal and coping. New York, NY: Springer.

Lightsey, O. R. Jr., \& Barnes, P. W. (2007). Discrimination, attributional tendencies, generalized self-efficacy, and assertiveness as predictors of psychological distress among African Americans, Journal of Black Psychology, 33, 27-50.

Major, B., Kaiser, C. R., \& McCoy, S. K (2003). It's not my fault: When and why attributions to prejudice protect self-esteem. Personality and Social Psychology Bulletin, 29, 772-781.

Major, B., Quinton, W. L., \& McCoy, S. K. (2002). Antecedents and consequences of attributions to discrimination: Theoretical and empirical advances. In M. P. Zanna (Ed.), Advances in Experimental Social Psychology, Vol. 34, (pp.251-330). San Diego, CA: Academic Press.

Mallet, R. K., \& Swim, J. K. (2005). Bring it on: Proactive coping with discrimination. Motivation and Emotion, 29, 411-441.

Matheson, K. \& Anisman, H. (2003). Systems of coping associated with dysphoria, anxiety, and depressive illness: A multivariate profile perspective. Stress, 6, 223-234. 
Coping with discrimination over time

Matheson, K., Gill, R., Kelly, O., \& Anisman, H. (2008). Cortisol and cardiac reactivity in the context of sex discrimination: The moderating effects of mood and perceived control. The Open Psychology Journal, 1, 1-10.

Matheson, K., Jorden, S., \& Anisman, H. (2008). Relations between trauma experiences and psychological, physical and neuroendocrine functioning among Somali refugees: Mediating role of coping with acculturation stressors. Journal of Immigrant and Minority Health, 10, 291-304.

McCarthy, J. D. \& Zald, M. N. (1977). Resource mobilization and the social movement: A partial theory. American Journal of Sociology, 82, 1212-1241.

McClelland, G. H., \& Judd, C. M. (1993). Statistical difficulties of detecting interactions and moderator effects. Psychological Bulletin, 114, 376-390.

McCoy, S. K., \& Major, B. (2003). Group identification moderates emotional responses to perceived prejudice. Personality and Social Psychology Bulletin, 29, 1005-1017.

Noh, S., Beiser, M., Kaspar, V., Hou, F., \& Rummens, J. (1999). Perceived racial discrimination, depression and coping: A study of southeast Asian refugees in Canada. Journal of Health and Social Behavior, 40, 193-207.

Noh, S., \& Kaspar, V. (2003). Perceived discrimination and depression: Moderating effects of coping, acculturation and social support. American Journal of Public Health, 93, 232238.

Operario, D., \& Fiske, S. T. (2001). Ethnic identity moderates perceptions of prejudice: Judgements of personal versus group discrimination and subtle versus blatant bias. Personality and Social Psychology Bulletin, 27, 550-561. 
Pennebaker, J. W., \& Chung, C. K. (2007). Expressive writing, emotional upheavals and health.

In H. S. Friedman \& R. C. Silver (Eds.), Foundations of health psychology (pp. 263-284). New York, NY, US: Oxford University Press.

Peters, R. M. (2006). The relationship of racism, chronic stress emotions, and blood pressure. Journal of Nursing Scholarship, 38, 234-240.

Rappaport, J. (1985). The power of empowerment language. Social Policy, 17, 15-21.

Reserdorff, S., Martinot, D., \& Branscombe, N. (2004). The impact of thinking about groupbased disadvantages or advantages on women's well-being: An experimental test of the rejection identification model. Current Psychology of Cognition, 22, 203-222.

Riger, S. (1993). What's wrong with empowerment. American Journal of Community Psychology, 21, 279-293.

Romero, A. J., \& Roberts, R. E. (2003). The impact of multiple dimensions of ethnic identity on discrimination and adolescents' self-esteem. Journal of Applied Social Psychology, 33, 2288-2305.

Rothbaum, F. M., Weisz, J. R., \& Snyder, S. S. (1982). Changing the world and changing the self: A two-process model of perceived control. Journal of Personality and Social Psychology, 42, 5-37.

Runciman, W. G. (1966). Relative deprivation and social justice: A study of attitudes to social inequality in twentieth century England. Berkeley, CA: University of California Press.

Schmitt, M. T., \& Branscombe, N. R. (2002). The internal and external causal loci of attributions to prejudice. Personality and Social Psychology Bulletin, 28, 620-628. 
Coping with discrimination over time

Schmitt, M. T., Branscombe, N. R., Kobrynowicz, D. \& Owen, S. (2002). Perceiving discrimination against one's gender group has different implications for well-being in women and men. Personality and Social Psychology Bulletin, 28, 197-210.

Schmitt, M. T., Branscombe, N. R., \& Postmes, T. (2003). Women's emotional responses to the pervasiveness of gender discrimination. European Journal of Social Psychology, 33, 112.

Schwarzer, R. \& Schwarzer, C. (1996). A critical survey of coping instruments. In M. Zeidner and N. S. Endler (Eds.), Handbook of Coping: Theory, research and applications (pp. 107-132). New York, NY, US: John Wiley \& Sons. Inc.

Scott, L. D. Jr., \& House, L. E. (2005). Relationship of distress and perceived control to coping with perceived racial discrimination among black youth. Journal of Black Psychology, $31,254-272$.

Seligman, M. E. P. (1975). Helplessness: On depression, development and death. San Francisco: Freeman.

Skinner, B. F. (1971). Beyond freedom and dignity. New York, NY: Knopf.

Swim, J. K., Hyers, L. L., Cohen, L. L., Ferguson, M. J. (2001). Everyday sexism: Evidence for its incidence, nature and psychological impact from three daily diary studies. Journal of Social Issues, 57, 31-53.

Skomorovsky, A., Matheson, K., \& Anisman, H. (2006). The buffering role of social support perceptions in relation to eating disturbances among women in abusive dating relationships. Sex Roles, 54, 627-638. 
Tabachnick, B. G. \& Fidell, L. S. (2007). Using multivariate statistics. Boston, MA: Allyn \& Bacon.

Tajfel, H., \& Turner, J. C. (1979). An integrative theory of intergroup conflict. In W. G. Austin \& S. Worchel (Eds.), The social psychology of intergroup relations. Monterey, CA: Brooks/Cole.

Taylor, D. M., \& McKirnan, D. J. (1984). A five-stage model of intergroup relations. British Journal of Social Psychology, 23, 291-300.

Taylor, D. M., Wright, S. C., Moghaddam, F. M. \& Lalonde, R. N. (1990). The personal/group discrimination discrepancy: Perceiving my group, but not myself, to be a target for discrimination. Personality and Social Psychology Bulletin, 16, 254-263.

Taylor, D. M., Wright, S. C., \& Porter, L. E. (1994). Dimensions of perceived discrimination: The personal/group discrimination discrepancy. In M. P. Zanna \& J. M. Olson (Eds.), The psychology of prejudice: The Ontario symposium (Vol. 7, pp. 233-255). Hillsdale, NJ: Lawrence Erlbaum.

Taylor, S. E., Kemeny, M. E., Reed, G. M., Bower, J. E., \& Gruenewald, T. L. (2000). Psychological resources, positive illusions and health. American Psychologist, 55, 99109.

Treharne, G. J., Lyons, A. C., Booth, D. A., Kitas, G. D. (2007). Psychological well-being across 1 year with rheumatoid arthritis: Coping resources as buffers of perceived stress. British Journal of Health Psychology, 12, 323-345.

Verkuyten, M. (2002). Perceptions of ethnic discrimination by minority and majority early adolescents in the Netherlands. International Journal of Psychology, 37, 321-332. 
Verkuyten, M., \& Nekuee, S. (2001). Self-esteem, discrimination and coping among refugees:

The moderating role of self-categorization. Journal of Applied Social Psychology, 31, 1058-1075.

Wright, S. C., Taylor, D. M., \& Moghaddam, F. M. (1990). Responding to membership in a disadvantaged group: From acceptance to collective protest. Journal of Personality and Social Psychology, 58, 994-1003. 
Table 1

Means and standard deviations for all measures

\begin{tabular}{lll}
\multicolumn{2}{l}{ Complete sample $(\mathrm{N}=73)$} & \multicolumn{2}{l}{ Sub-sample $(\mathrm{n}=31)$} \\
$M \quad S D$ & $M \quad S D$
\end{tabular}

Time 1 variables

Pervasiveness

$.82 \quad 1.05$

$.62 \quad .93$

Experimenter bias

$.30 \quad .95$

$.57 \quad .94$

Action**

$.10 \quad .26$

$.66 \quad .97$

Acceptance

$2.34 \quad 1.39$

$2.17 \quad 1.57$

Emotional containment

$.86 \quad 1.22$

$.93 \quad .91$

Mood (negative)

$.76 \quad .56$

$.89 \quad 1.46$

Self-esteem

$2.65 \quad .72$

$2.87 \quad .68$

Time 2 variables

Mood (unhappiness)

24.4815 .74

Self-esteem

$.82 \quad .58$

Physical symptoms

$.51 \quad .32$

Note. Measures ranged from 0 to 4 with the exception of Time 2 variables: unhappiness ( 0 to $100 \%$ ), self-esteem and physical symptoms (0 to 3 ). ** refers to significant differences between the two samples at $\mathrm{p}<.001$. 
Table 2

Intercorrelations among variables

\begin{tabular}{lllllllllllll}
\hline 1 & 2 & 3 & 4 & 5 & 6 & 7 & 8 & 9 & 10 \\
\hline
\end{tabular}

Time 1 variables $(\mathrm{N}=73)$

1. Pervasiveness --

2. Experimenter bias $.25 \quad--$

3. Action $\quad .25 \quad .36^{*}--$

4. Acceptance $\quad-.21 \quad-.06 \quad-.28 \quad--$

5. Emotional

$\begin{array}{llllll}\text { containment } & .40 * & .38 & .15 & .12 & --\end{array}$

6. Mood (negative) $\quad .42 * * \quad .32 * \quad .43 * \quad-.31 * \quad .49 * * \quad--$

$\begin{array}{lllllll}\text { 7. Self-esteem } & -.57 * * & -.21 & -.23 & .30 * & -.48 * * & -.52 * *\end{array}$

$\underline{\text { Time } 2 \text { variables }(\mathrm{n}=31)}$

8. Mood

$\begin{array}{lllllllll}\text { (unhappiness) } & .28 & .44 * & .31 & .13 & .35 \dagger & .29 & -.08 & --\end{array}$

$\begin{array}{lllllllllll}\text { 9. Self-esteem } & -.21 & -.17 & .09 & -.23 & -.19 & -.23 & .25 & -.35 \dagger & --\end{array}$

10. Physical

$\begin{array}{lllllllllll}\text { symptoms } & .04 & -.19 & -.14 & .19 & .09 & -.24 & .13 & .46^{*} & .35 \dagger & -\end{array}$

Note. $\dagger p<.06 . * p<.05 . * * p<.01$. 
Table 3

Summary of hierarchical regressions

Dependent

variables

Step Predictors

$B \quad S E B \quad \beta \quad \mathrm{R}_{\text {change }}^{2}$

Time 1 variables

\begin{tabular}{|c|c|c|c|c|c|c|}
\hline \multirow{2}{*}{$\begin{array}{l}\text { Mood } \\
\text { (Negative affect) }\end{array}$} & 1 & Pervasive discrimination & .64 & .23 & \multicolumn{2}{|l|}{$.44 * *$} \\
\hline & & Action & .33 & .15 & $.35^{*}$ & $.387 * *$ \\
\hline & 2 & Interaction & .42 & .09 & $.67 * *$ & $.296 * *$ \\
\hline & 1 & Experimenter bias & .26 & .40 & .13 & \\
\hline & & Action & .37 & .20 & $.38 \dagger$ & $.209 \dagger$ \\
\hline & 2 & Interaction & .57 & .27 & $.52 *$ & $.130 *$ \\
\hline & 1 & Pervasive discrimination & .76 & .24 & $.52 * *$ & \\
\hline & & Accept & .22 & .24 & .15 & $.296 * *$ \\
\hline & 2 & Interaction & -.07 & .29 & -.05 & .002 \\
\hline & 1 & Experimenter bias & .56 & .39 & .29 & \\
\hline & & Accept & .10 & .32 & .06 & .093 \\
\hline & & Interaction & .10 & .53 & .05 & .001 \\
\hline & 1 & Pervasive discrimination & .50 & .23 & $.34^{*}$ & \\
\hline & & Emotional containment & .72 & .25 & $.45^{* *}$ & $.446^{* *}$ \\
\hline & 2 & Interaction & .79 & .10 & $.74 * *$ & $.389 * *$ \\
\hline
\end{tabular}


Dependent

$\begin{array}{lllllll}\text { variables } & \text { Step } & \text { Predictors } & B & S E B & \beta & \mathrm{R}_{\text {change }}^{2}\end{array}$

\begin{tabular}{|c|c|c|c|c|c|c|}
\hline & 1 & Experimenter bias & .39 & .33 & .20 & \\
\hline & & Emotional containment & .88 & .27 & $.54 * *$ & $.372 * *$ \\
\hline & 2 & Interaction & .86 & .28 & $.46^{* *}$ & $.179 * *$ \\
\hline \multirow[t]{14}{*}{ Self-esteem } & 1 & Pervasive discrimination & -.24 & .12 & $-.35 \dagger$ & \\
\hline & & Action & -.07 & .08 & -.15 & .172 \\
\hline & 2 & Interaction & -.08 & .06 & -.28 & .052 \\
\hline & 1 & Experimenter bias & .24 & .19 & .28 & \\
\hline & & Action & -.14 & .09 & -.33 & .110 \\
\hline & 2 & Interaction & .05 & .14 & .10 & .005 \\
\hline & 1 & Pervasive discrimination & -.21 & .12 & $-.31 \dagger \dagger$ & \\
\hline & & Accept & .18 & .12 & .27 & $.218 *$ \\
\hline & 2 & Interaction & -.25 & .13 & $-.34 \dagger$ & $.096 \dagger$ \\
\hline & 1 & Experimenter bias & .02 & .15 & .03 & \\
\hline & & Accept & .11 & .18 & .17 & .018 \\
\hline & 2 & Interaction & -.22 & .24 & -.24 & .037 \\
\hline & 1 & Pervasive discrimination & -.21 & .13 & -.31 & \\
\hline & & Emotional containment & -.15 & .14 & -.20 & .18 \\
\hline
\end{tabular}


Dependent

variables

Step Predictors

$B \quad S E B \quad \beta \quad \mathrm{R}_{\text {change }}^{2}$

2 Interaction

$\begin{array}{llll}-.08 & .10 & -.16 & .018\end{array}$

$1 \quad$ Experimenter bias

$\begin{array}{lll}-.19 & .15 & -.27\end{array}$

Emotional containment

$\begin{array}{llll}-.11 & .15 & -.16 & .141\end{array}$

2 Interaction

$\begin{array}{llll}-.25 & .16 & -.31 & .079\end{array}$

Time 2 variables

\begin{tabular}{|c|c|c|c|c|c|c|}
\hline Mood & 1 & Pervasive discrimination & 3.52 & 2.95 & .22 & \\
\hline (Unhappiness) & & Action & 2.61 & 1.92 & .25 & .138 \\
\hline & 2 & Interaction & .122 & 4.55 & .02 & .000 \\
\hline & 1 & Experimenter bias & 8.12 & 4.45 & $.38 \dagger$ & \\
\hline & & Action & 1.48 & 2.19 & .14 & $.209 \dagger$ \\
\hline & 2 & Interaction & -1.51 & 3.29 & -.13 & .008 \\
\hline & 1 & Pervasive discrimination & 4.81 & 3.09 & .30 & \\
\hline & & Accept & .99 & 3.09 & .06 & .083 \\
\hline & 2 & Interaction & 2.10 & 3.48 & .12 & .013 \\
\hline & 1 & Experimenter bias & 9.33 & 4.12 & $.43^{*}$ & \\
\hline & & Accept & .70 & 3.36 & .04 & $195 \dagger i$ \\
\hline & 2 & Interaction & 11.71 & 4.96 & $.50 *$ & $.162 *$ \\
\hline
\end{tabular}


Dependent

variables

Step Predictors

$B \quad S E B \quad \beta \quad \mathrm{R}_{\text {change }}^{2}$

\begin{tabular}{|c|c|c|c|c|c|c|}
\hline & 1 & Pervasive discrimination & 2.69 & 3.12 & .17 & \\
\hline & & Emotional containment & 4.89 & 3.39 & .28 & .145 \\
\hline & 2 & Interaction & .62 & 2.48 & .05 & .002 \\
\hline & 1 & Experimenter bias & 8.42 & 3.29 & $.39 *$ & \\
\hline & & Emotional containment & 4.89 & 3.25 & .27 & $.266^{*}$ \\
\hline & 2 & Interaction & 7.43 & 3.75 & .36 & $.111 * *$ \\
\hline \multirow[t]{10}{*}{ Self-esteem } & 1 & Pervasive discrimination & .11 & .11 & .20 & \\
\hline & & Action & .02 & .07 & .04 & .044 \\
\hline & 2 & Interaction & .02 & .08 & .05 & .000 \\
\hline & 1 & Experimenter bias & -.19 & .18 & -.24 & \\
\hline & & Action & .06 & .09 & .17 & .051 \\
\hline & 2 & Interaction & -.02 & .13 & -.05 & .001 \\
\hline & 1 & Pervasive discrimination & .09 & .11 & .16 & \\
\hline & & Accept & -.10 & .11 & -.17 & .068 \\
\hline & 2 & Interaction & .07 & .13 & .11 & .009 \\
\hline & 1 & Experimenter bias & -.13 & .12 & -.21 & \\
\hline
\end{tabular}


Dependent

variables

Step Predictors

$B \quad S E B \quad \beta \quad \mathrm{R}_{\text {change }}^{2}$

\begin{tabular}{|c|c|c|c|c|c|c|}
\hline & & Accept & -.11 & .16 & -.14 & .072 \\
\hline & 2 & Interaction & -.01 & .16 & -.02 & .001 \\
\hline & 1 & Pervasive discrimination & .09 & .12 & .15 & \\
\hline & & Emotional containment & .09 & .13 & .13 & .058 \\
\hline & 2 & Interaction & -.06 & .10 & -.14 & .013 \\
\hline & 1 & Experimenter bias & -.09 & .14 & -.13 & \\
\hline & & Emotional containment & .02 & .07 & .05 & .020 \\
\hline & 2 & Interaction & .59 & .31 & $.95 \dagger$ & $.159 \dagger$ \\
\hline Physical & 1 & Pervasive discrimination & .03 & .06 & .08 & \\
\hline \multirow[t]{8}{*}{ Symptoms } & & Action & -.03 & .0 & -.16 & .025 \\
\hline & 2 & Interaction & -.04 & .03 & -.12 & .007 \\
\hline & 1 & Experimenter bias & -.07 & .09 & -.17 & \\
\hline & & Action & -.02 & .05 & -.07 & .043 \\
\hline & 2 & Interaction & -.09 & .07 & -.38 & .069 \\
\hline & 1 & Pervasive discrimination & .03 & .06 & .11 & \\
\hline & & Accept & .07 & .06 & .23 & .049 \\
\hline & 2 & Interaction & .07 & .07 & .21 & .037 \\
\hline
\end{tabular}


Dependent

variables

Step Predictors

$\begin{array}{llll}B & S E B & \beta & \mathrm{R}_{\text {change }}^{2}\end{array}$

\begin{tabular}{lllllll}
\hline 1 & Experimenter bias & -.09 & .08 & -.23 & \\
& & Accept & .08 & .06 & .23 & .104 \\
2 & Interaction & .04 & .08 & .09 & .007 \\
1 & Pervasive & .01 & .07 & .01 & \\
& & Emotional containment & .03 & .07 & .09 & .009 \\
& & Interaction & -.08 & .05 & -.37 & .095 \\
& & Experimenter bias & .14 & .27 & .11 & \\
& Emotional containment & .13 & .13 & .21 & .048 \\
& Interaction & 1.09 & .56 & $.93 \dagger$ & $.136 \dagger$ \\
& & & & & \\
\hline
\end{tabular}

Note. $\dagger \dagger p<.08 . \dagger p<.06 . * p<.05 . * * p<.01$. 